\title{
O discurso crítico e a Abstração Informal: da contradição à revisão de conceitos
}

\section{ALMERINDA DA SILVA LOPES}

\section{Resumo}

A projeção da Abstração Informal no pós-guerra gerou a necessidade de construir um novo vocabulário crítico que, somado às disputas pela hegemonia artística e por um mercado em afirmação, transformou essa vanguarda estética no estuário para onde iriam convergir inúmeras reflexões, interesses e posicionamentos críticos, polêmicos e contraditórios.

Palavras-chave: Abstração Informal, Pintura Abstrata, crítica de arte, modernismo 


\title{
Critical Speech and Informal Abstraction: from contradiction to review the concepts
}

\author{
ALMERINDA DA SILVA LOPES
}

\section{Abstract}

The projection of post-war Informal Abstraction developed the necessity to construct a new critical vocabulary, added to disputes for artistic hegemony and a market in

Keywords: Informal Abstraction, Abstract Painting, art review, modernism accordance, changed this heroic vanguard into a place for several reflections, polemic and contradictory interests and esteemed critical positions. 
0 registro, desde longa data de elementos abstratos em artefatos e toda a diversidade de objetos utilitários e ritualísticos de barro, couro e madeira, incisões em superfícies de pedra e pinturas produzidas por povos ancestrais, desde o neolítico, passando por antigas civilizações, períodos iconoclastas (islâmicos, bizantinos), até criações pictóricas mais próximas do nosso tempo, não deixam dúvida que o homem, antes mesmo de se dedicar à imitação das coisas do mundo que o cercava, expressou-se ou se comunicou por meio de formas abstratas.

E se existem registros de formulações geométricas e signos orgânicos desde os primórdios da humanidade, porque razão, quando do surgimento dos movimentos artísticos de natureza não figurativa no século $\mathrm{XX}$, os mesmos terem causado toda a sorte de polêmica gerada pela crítica? E como explicar o longo período de rejeição e exclusão da abstração do âmbito das instituições culturais?

O distanciamento no tempo permite-nos hoje discorrer com maior compreensão e alguma consistência sobre a relevância das premissas postuladas pelos artistas abstracionistas e a estupenda projeção e aceitação que essa linguagem teria mais recentemente. E se somarmos a isso os rumos empreendidos pela arte a partir do final da década de 1950, o grau de intolerância da crítica francesa à abstração, de modo especial à tendência informal acentua-se, e boa parte dos discursos emitidos sobre ela parece-nos ainda mais paradoxal.

Vale considerar preliminarmente que, desde o início do século XIX até a propagação do Impressionismo, o emprego de termos como abstrato e abstrair iria se tornar cada vez mais freqüente nos escritos de alguns teóricos e artistas, embora com o intuito de opor as novas gramáticas visuais aos léxicos anteriores, e não com o sentido que os termos assumiriam depois. 
No limiar do século passado, um número cada vez mais expressivo de artistas europeus passou a desenvolver pesquisas individuais que propugnavam a substituição dos códigos representativos por formas e signos não figurativos ou abstratos, sendo atribuída ao russo Wassily Kandinsky, pela maioria dos historiadores da arte, a posição de deflagrador desse processo criativo. Essa posição tem sido, porém questionada por teóricos contemporâneos, que consideram que esse investimento não teria sido individual, nem ocorreu de maneira casual e isolada como alguns historiadores admitiram. Ao contrário, o aparecimento de formulações abstratas manifestou-se de maneira praticamente simultânea, na produção de artistas de diferentes continentes. Por diferentes caminhos e propósitos, e talvez sem se comunicarem, artistas de regiões distantes iriam chegar a denominadores comuns, confirmando que a pesquisa de novas gramáticas visuais foi provocada por uma necessidade ou anseio coletivo, ou quem sabe, universal. ${ }^{1}$

Assim, o conceito de Abstração embora fosse aprofundado e ampliado após o surgimento de movimentos artísticos pautados nesse léxico, no início do século XX, a origem de termos como "abstrato" e "abstração" não é recente, considerando que, na língua francesa e inglesa remontam à Idade Média (LEBENSTEJN, 2009, p.8).

Entretanto, o sentido que os termos tinham então, diferenciava-se daquele que as formas abstratas iriam assumir no campo artístico mais recentemente. A primeira das duas tendências, a Abstração Geométrica, começaria se firmar e definir suas premissas estéticas, durante e após a Primeira Guerra Mundial, contaminando rapidamente artistas de todas as latitudes. Assumiria denominações próprias, nos países onde mais se desenvolveram os conceitos e postulados poéticos das duas gramáticas formais, mesmo que eles não se revelassem, necessariamente, simétricos ou equânimes.

Isso significa que, a criação, no mundo ocidental, de movimentos artísticos, centrados em experiências e axiomas específicos sobre as linguagens e os processos abstratos, deu-se somente com as chamadas vanguardas. Quando surgiram, de maneira quase simultânea, essas tendências não iriam se colocar em oposição, pois não deixavam de respaldar-se em premissas ou aspirações aparentemente comuns: romper com os valores do passado, refutando a representação ilusionista do mundo objetivo ou analógico.

Com o desenvolvimento das pesquisas e adesão de um número cada vez mais expressivo de artistas, se definiam as 
variações dessas gramáticas, que não pleiteavam se instituir como oposições, mas como reversos de um mesmo pensamento poético ou proposição criativa. Assim, tanto a abstração de natureza construtiva, quanto a informal ou lírica, pleiteavam se instituir como movimentos artísticos autônomos, cujos elementos formais substituíam os tradicionais códigos icônicos, por signos não representativos.

A antiga idéia de imitar as coisas do mundo objetivo, por meio de artifícios visuais sobre uma superfície planar, cedia lugar a léxicos centrados, de um lado, no rigor e precisão de geometria - que alguns chamavam de formas de compreensão universal -, enquanto que os elementos visuais da outra tendência assumiam uma configuração mais maleável: formulada por arcabouços imprecisos, manchas irregulares, formas orgânicas ou biomórficas, de natureza subjetiva. Portanto, os respectivos axiomas conceituais e estéticos, iriam fazer as duas modalidades de abstração "oscilar entre os pólos da razão e do instinto, da construção e do lirismo" (DAVAL, 1988, p. 127).

Num mundo fortemente pautado na razão, a tendência informal ou lírica, por ser relacionada com o mundo subjetivo e a irracionalidade, iria ter ainda maior dificuldade para se expandir, e angariar reconhecimento e aceitação, gerando muito mais embates entre seus defensores e opositores, do que a geométrica. Nos anos que se seguiram à Segunda Guerra iria dividir a crítica em dois grupos antagônicos: o que entendia essa linguagem como uma gramática pautada na subjetividade e na expressividade, e portanto, em sintonia com o clima o momento; e o que se opunha a ela, tentando salvaguardar a soberania da tendência geométrica ou racional. Se tais interesses e divergências não impediram que a pintura informal se propagasse pelo mundo, isso somente iria ocorrer no final da década de 1940, quando se tornou verdadeiro fenômeno pictórico no mundo. Permaneceria, entretanto, pouco tempo em cena, pois ao final dos anos de 1950 cederia a vez ao espírito jocoso, descontraído e de fácil digestão das novas figurações pop.

A atrocidade da Guerra e a Ocupação da capital francesa (1940-1944) puseram à prova ou em dúvida os investimentos na razão, tornando o momento propício ao desenvolvimento da Abstração Informal, tendência essa antecipada por Fautrier, que causaria grande impacto ao expor pela primeira vez a série de Otages (1942), o mesmo ocorrendo com as aquarelas e pinturas de Wols, mostradas em Paris, respectivamente em 1945 e 1947. Por outro lado, o estado de crise e o recrudescimento dos acontecimentos políticos que marcariam a França 
no pós-guerra, entre eles o fortalecimento do Partido Comunista (1947-1953), ${ }^{2}$ tencionariam o interesse de alguns artistas para o lado oposto, fazendo com que nomes já estabelecidos como Léger e Picasso refutassem, contraditoriamente, a Abstração, posicionando-se em favor do realismo socialista.

Se a Abstração Informal ou Lírica na Europa surgia em meio a esse conflito de interesses e forças, isso não impediu que muitos artistas pautassem sua praxe em uma profusão de gestos, signos e cores explosivas ou soturnas. Sintonizavam, assim, o próprio fazer artístico com o tempo existencial, isto é, com o estado de instabilidade e de depressão, estabelecendo assim "uma ponte mais direta arte-vida, como haviam tentado antes os futuristas italianos e o Dada", como bem observou Enrico Crispolti (1971, p. 24). Mas além do estado de instabilidade e crise, pesava sobre os ombros da França a longa tradição das gramáticas figurativas, que perduraria até as vanguardas, o que explica de alguma maneira, a razão de parte da crítica não ter visto de bom grado a ascensão da Abstração, chegando mesmo a refutá-la, laçando contra ele a pecha de modismo internacional.

Em contrapartida, o Expressionismo Abstrato e a Action Painting (Pintura Gestual ou de Ação) - denominações que a abstração não geométrica recebeu nos Estados Unidos - foram exaltados, pela crítica americana com grande entusiasmo. Clement Greenberg e outros confrades iriam conectar essa gramática expressiva ao espírito jovial, moderno e impetuoso da vida americana, além de associá-la ao ideal de liberdade tão almejado e propalado no pós-guerra. Tais posicionamentos explicam, por si só, o enorme vácuo existente entre as duas realidades.

País jovem, livre do fardo da tradição, passando por situação política privilegiada, em relação a uma Europa deprimida e esfacelada pela Guerra, os Estados Unidos, por não terem participado do conflito mundial saíram fortalecidos, e beneficiavam-se do excepcional boom que sua economia atingia no pós-guerra. Assim, os gestos largos, impulsivos e descontraídos, não seriam motivo para rejeitar essa nova pintura, ou para censurar seus respectivos signatários.

Ao contrário, essa pintura seria aclamada pelo público, pela crítica e pelas instituições, o que fazia do Expressionismo Abstrato e da Action Painting poéticas afirmativas do chauvinismo americano daquele momento. A euforia se justificava, pois os americanos iriam associar essas composições, elaboradas com trinchas carregadas de matéria, em pinceladas am- 
plas e vigorosas e cores orquestrais, ou com tintas respingadas, lançadas livre e diretamente sobre os gigantescos suportes de lona, com a jovialidade e o espírito democrático daquele país. A crítica americana, liderada por Greenberg, recorreu a um discurso direto, engajado, perspicaz e convincente, a crítica iria reforçar o discurso ufanista americano, proclamando a superioridade da abstração americana no mundo ocidental, como meio de reverter a baixa reputação desfrutada no pós-guerra pela cultura ianque.

Entretanto, esse posicionamento não seria percebido pela crítica francesa. Ao discorrer sobre a Abstração Lírica ou Informal - também chamada por alguns de Tachismo - (expressão criada por Pierre Guégen, em 1951, para se referir às manchas e respingos), não iria revelar habilidade e poder de persuasão. Pautando-se em discursos tímidos ou pouco convictos sobre essa praxe artística, ou quanto ao seu significado de uma poética articulada por signos caligráficos e gestos matéricos, a crítica ainda acusava os artistas de lançar as tintas nas telas, de maneira improvisada ou ao acaso.

Os franceses não iriam se reconhecer nas linguagens abstratas, ao chamá-las de "modismo estrangeiro", nem atinar para a notável contribuição de uma plêiade de artistas estrangeiros - que se fixaram em Paris durante e após o conflito bélico - para a formulação da gramática informal francesa. Tal posição colocaria as gramáticas abstratas francesas, em posição de inferioridade e iria postergar a penetração das mesmas nas instituições e coleções daquele país.

Os artistas pareciam indiferentes aos impropérios dirigidos aos seus léxicos, não se envolvendo na polêmica, preferindo envolver-se antes no corpo a corpo com a pintura. Atuavam isolados, imbricando nas respectivas telas processo/ ação/reflexão/criação, conscientes de que o ato pictórico é o resultado de uma vivência ou um processo de entropia: nasce de uma necessidade interior e, portanto, não precisa ser demonstrada como válida, ou teorizada, fatores suficientes para justifica a elaboração das obras.

Por essas e por outras razões, que deixaremos de destacar, nos anos imediatamente posteriores à Guerra, a Abstração Informal seria avaliada com excessiva cautela, por uns e com desconfiança e impropérios por outros, postergando-se assim a sua exposição e incorporação ao acervo das instituições culturais francesas.

Basta citar que mesmo depois da reinauguração e abertura ao público do Museu de Arte Moderna de la Ville de Paris, 
em 1947 - depois de permanecer fechado longo tempo para reformulação - a instituição ao iria expor e adquirir telas informais, a não ser muitos anos depois. E se é verdade que a partir da segunda metade da década de 1950, um número mais expressivo de críticos procuraria discorrer sobre a gramática informal, com maior convicção ou menos preconceito, esta continuaria a ser alvo de embates, polêmica e discursos contraditórios ou evasivos, por parte de seus opositores.

Esses fatores se não impediram que a Abstração se desenvolvesse e recebesse a adesão de jovens iniciantes e de notáveis artistas já estabelecidos naquele país, pelos fatores apontados foi alvo de incompreensão e teve sua aceitação e assimilação retardadas, o que contribuiu indubitavelmente para que os Estados Unidos assumisse logo depois da Guerra, a posição de capital artística do mundo, anunciando na Partisan Review (1948), a decadência da "Escola de Paris" e destacando a emergência explosiva da Escola de Nova York.

O peso da tradição figurativa iria levar os franceses a refutar a abstração desde muito antes, ou desde que surgiram em Paris alguns esparsos grupos de abstracionistas geométricos, sendo o mais conhecido Circle et Carré (Circulo e Quadrado), liderado pelo uruguaio ali radicado, Joaquim Torres Garcia, e pelo artista e teórico Michel Seuphor (1929). Mesmo chegando a congregar cerca de oitenta artistas, o grupo não iria receber o necessário apoio aos eventos e publicações da revista criada pelo grupo, o que explica sua curta existência.

Com o intuito de atenuar o preconceito da velha metrópole européia à arte abstrata era inaugurado em Paris, em 1943, o Salão de Realités Nouvelles. O evento não traria, porém, resultados satisfatórios, pelo menos imediatos, considerando que essa linguagem expressiva continuaria a ser alvo da intolerância e de análises contraditórias, ainda no final da década de 1950, conforme revelam os conturbados debates travados entre a crítica, numa época em que essa gramática já havia dado sinais de esgotamento nos países europeus onde mais se desenvolveu e projetou.

A crítica de arte francesa se mostrava, então, dividida em pelo menos duas facções: uma delas, provinciana, conservadora ou retrógrada, continuaria a tentar salvaguardar a tradição figurativa, propondo o "retorno à ordem"; enquanto o grupo oponente se mostrava mais aberto ao novo, e procurava, mesmo que sem grande astúcia ou argumentação mais persuasiva, associar os postulados expressivos da Abstração Lírica ao clima existencial do pós-guerra. 
Os primeiros atacavam a linguagem informal, chamando-a de "corruptora do espírito", "arte lúdica", "transcendental", "modismo internacional", responsável pela "degradação da sensibilidade e da consciência" e por propugnar a "desnacionalização da arte francesa". Essa vertente pictórica era também considerada por alguns, como sendo processo de regressão criativa, arte fugaz, vazia ou desprovida de conteúdo estético, e de elaboração formal inconseqüente, o que corrompia os valores e significados artísticos e desvirtuava o sentimento nacional.

Assim, de nos anos de maior desenvolvimento e projeção das linguagens não figurativas no mundo a crítica francesa não conseguiria discorrer com maior convicção sobre o abstracionismo informal, Greenberg se mostrava mais preparado e ardiloso. Valendo-se, entre outras questões, de um discurso direto e de grande poder de persuasão, ajudou a proclamar a superioridade do Expressionismo Abstrato americano, que dizia ser a linguagem mais original e "avançada", surgida em todo o mundo.

Greenberg não negaria a herança recebida dos modernistas franceses para a renovação das linguagens artísticas nos Estados Unidos. Ao contrário, destacou o significado da presença de artistas europeus em Nova York, "durante os anos da guerra como Mondrian, Masson, Léger, Chagall, Ernst e Lipchitz, bem como de muitos críticos, marchands e colecionadores". Mas o crítico também não deixava de destacar a ousadia do gesto dos artistas americanos que, segundo ele, souberam extrair da pintura francesa um "senso básico de estilo", ao mesmo tento em que se libertaram de determinadas imposições "programáticas", como alternativa tara testar e romper com "os limites das formas e gêneros herdados", e encontrar um caminho inventivo próprio para formular uma arte autêntica, resultante do cruzamento de aspectos herdados com elementos extraídos da cultura ancestral (GREENBERG, 1997, p. 77).

Se os abstracionistas informais franceses não encontraram o devido apoio e compreensão da crítica, também os marchands de arte figurativa, aos primeiros sinais de instabilidade econômica do pós-guerra, tentariam reverter a queda nas vendas voltando-se contra os léxicos abstratos. Posição semelhante era assumida, como já citado, por artistas reconhecidos e que disputavam até então boa fatia do mercado, com destaque para Picasso, Léger, André Lhote, Bernard Buffet, Fougeron. Simpatizantes, naquele momento, do realismo socialista, esses e outros pintores sentiam-se ameaçados em seu prestígio, pelo interesse vertiginoso que 
começavam a despertar nos marchands e no público as telas abstracionistas de Pollock, De Kooning, Gorky, Tobey, Rotthko, em diferentes países europeus.

E não demoraria muito para que as telas gigantescas produzidas por esses e outros artistas americanos começassem a ser adquiridas pelo empresariado, que deixaria de investir na pintura impressionista, e outras linguagens modernas europeias, para investir no Expressionismo Abstrato. Logo após o término da Guerra eram inauguradas em Paris galerias especializadas em arte abstrata, enquanto que outras - antes voltadas exclusivamente para as tendências figurativas -, logo passariam a expor e comercializar também trabalhos abstratos (geométricos e informais), de artistas europeus e americanos.

A contribuição, mesmo que isolada, do pintor e teórico Georges Mathieu também não pode ser menosprezada. Ao retornar a Paris, depois de realizar viagem dos Estados Unidos - ali presenciando a euforia em torno do Expressionismo Abstrato, e onde se deixaria contaminar por aquele léxico passava a executar, a partir de 1947, pinturas informais sobre grandes suportes. Nelas revelaria interesse particularmente pela pintura de Pollock, o que transparece na recorrência a gotejados e a gestos enovelados, construídos muitas vezes com a tinta esguichada diretamente das bisnagas.

Todavia, mais que a praxe e a poética do artista, o que iria provocar reações extremadas de alguns críticos e instigar os interlocutores eram os títulos irônicos com que o artista costumava nomear suas telas. Por meio deles remetia a fatos e personagens históricos e culturais, peculiaridade que talvez possa ser tributada a Motherwell, artista americano que também costumava batizar suas telas abstratas com títulos históricos (a exemplo de Elegy for the Spanish Republic, 1954).

Mathieu também iria organizar na Galeria de Montparnasse (1948), a primeira mostra que teve a intenção de pôr em confronto a tímida Abstração Informal francesa, com os gigantescos painéis de exuberante e o desbragado vigor de formas e cores de autoria dos congêneres americanos. ${ }^{3} \mathrm{~A}$ repercussão do gesto do artista parece ter sido maior do que a que ele certamente anteviu, pois essa mostra causar grande impacto e despertar o interesse dos marchands, que apostando no sucesso das vendas das telas abstracionistas francesas, iriam inaugurar galerias especializadas, e criar revistas voltadas para a difusão da pintura abstrata. 
O objetivo desses periódicos era divulgar o trabalho dos artistas representados pelas galerias e incentivar a formação de uma nova crítica, disposta a refletir sobre essa produção, recorrendo a uma argumentação capaz de modificar a compreensão da poética abstracionista local, e estabelecer um diálogo com a gramática congênere de nomes de projeção internacional.

Em virtude de sua formação filosófica e de sólida formação intelectual, Mathieu, além de pintor de telas informais, também iria legar à França uma significativa produção teórica sobre a Abstração Informal: publicação de livros, textos em revistas especializadas, depoimentos, alguns dos quais teriam ampla repercussão no Brasil, como veremos..

\section{A criação de revistas especializadas e a reformulação do conceito de abstração}

Se a atitude tomada por Georges Mathieu parecia confirmar que diante da ameaça da supremacia da arte americana era necessário que os franceses encontrassem a saída da profunda e persistente letargia artística, para que a abstração se afirmasse, despertasse o interesse do público e do mercado, e rompesse as fronteiras territoriais. Para que isso de concretizasse seria necessário a formação de uma nova crítica, capaz de promover a revisão dos discursos, pautando-se em bases teóricas, e que facultasse maior compreensão das poéticas abstratas.

Com esse propósito eram criadas as primeiras revistas dedicadas à abstração: Art d'Aujourd 'hui, 1949, editada por André Bloc, daria ênfase à Abstração Geométrica e à Arquitetura moderna; e Cimaise, editada entre 1952 e 1959, em várias línguas, voltada para "a arte atual", era dirigida por J. R. Arnaud, proprietário da Galeria Arnaud. Grande parte dos textos críticos publicados pela última revista seria dedicada à Abstração Lírica francesa, embora também houvesse aqueles que iriam discorrer sobre a gramática pictórica americana, e os que estabeleciam diálogos entre a produção pictórica geométrica e a informal de diferentes países. ${ }^{4}$

$\mathrm{O}$ foco específico não impediu que os críticos que escreviam para esses periódicos assumissem às vezes posições contraditórias, ou defendessem diferenciados pontos de vista. Reflexões evasivas e pouco significativas sobre a pintura construtivas e a informal também se fariam notar, em especial, nos primeiros anos de circulação dos periódicos, tornando patente que o mofo da tradição francesa não seria facilmente elimi- 
nado, sem contar que nem todos os críticos assumiriam uma posição clara ou mais definida sobre as poéticas abstratas.

A criação de Art d'Aujourd 'hui pouco depois da já citada proclamação da superioridade da Escola de Nova York na Partisan Review, não parece ter sido mera coincidência. Basta mencionar o expressivo número de matérias publicadas pela crítica francesa, naquela revista, que revelam o esforço de conceituar e destacar a existência de uma Escola de Paris, e diferenciá-la da chamada Escola de Nova York, também chamada por alguns de Escola do Pacífico.

Em um texto denominado Alguns jovens americanos em Paris, publicado por ocasião da realização da mostra Véhémences Confrontées (1951), organizada por Georges Mathieu e Michel Tapié, na Galeria do Dragon, em Paris, de propriedade de Nina Dausset, o crítico Julien Alvard tentava promover a aproximação entre abstracionistas franceses e americanos, e reconhecia, num misto de verdade e ingenuidade, que a expressão Escola de Paris fora criada anos depois da emergência da congênere americana (ALVARD, 1961, p. 27).

O intervalo de três anos entre a criação das revistas citadas iria revelar considerável mudança na posição assumida pelos articulistas que escreviam para a Cimaise, em relação ao discurso da crítica ligada à Art d'Aujoud'hui. Os articulistas da primeira revista pareciam ter percebido a necessidade de lançar um olhar menos preconceituoso e contundente sobre a abstração, quando a vida social e política da França tornavam-se menos conturbadas.

Mas a queda do prestígio do Partido Comunista, que deixaria de interferir na produção artística iria refletir em mudança no discurso, também dos articulistas de vários outros órgãos da imprensa. Vale citar o caso do jornal Lettres Françaises que, de veículo de defesa das idéias comunistas e do realismo socialista, iria se mostrar simpatizante da Abstração Lírica e do Surrealismo Abstrato, notadamente a partir de 1953, quando assumiu a direção do periódico Maurice Nadeau.

As páginas das revistas Art d'Aujourd'hui e Cimaise abriam, então, espaço cada vez mais privilegiado para um persistente, e às vezes polêmico debate sobre o significado daquilo que se convencionou chamar Segunda Escola de Paris. Mas o assunto tornava-se um dos temas principais também dos articulistas de outros órgãos da imprensa. Com o intuito de tornar mais claro o processo seminal da Abstração, alguns críticos, a exemplo de Bernard Lourival, procediam a recuos no tempo, para explicar o surgimento de alguns dos mais 
marcantes movimentos abstracionistas geométricos, com destaque para o entre guerras. Esse antigo defensor do realismo social, que dominara os Salões de Outono, iria reconhecer, mesmo que tardiamente, o significado da obra de artistas como Bazaine, Ubac, Poliakoff, Manessier, Lanskoy, Estève, De Stael, Bissière, Lapicque, Zao Wou-Ki, para a renovação da linguagem artística francesa, em texto escrito por ele para o catálogo da mostra Os Anos 5o, realizada no Centro Cultural Georges Pompidou (1977).

O temário da Escola de Paris permaneceria ainda por muito tempo no centro dos debates das revistas francesas, o que permite reunir os discursos em torno de três questões fundamentais: os que defendem a consistência das gramáticas geométricas em relação à vertente lírica ou tachista; os que discorrem sobre o significado da Escola de Paris, para a formulação das linguagens abstratas; os que destacam as peculiaridades formais e cromáticas do léxico informal parisiense, para distingui-las das da tendência correlata nova-iorquina.

Assim, as abordagens dos articulistas de Art d'Aujourd 'hui centram forças na primeira problemática; nos textos da $\mathrm{Ci}$ maise predominariam as outras duas preocupações. Esse foi o caso de artigo de autoria de Herta Wescher, publicado nesse último periódico, que ao tentar comparar o estilo francês em oposição ao da Escola do Pacífico, ampliava ainda mais a polêmica, situando-as em duas polaridades: "formato limitado versus formato ilimitado, intensivo $x$ extensivo, interioridade $\mathrm{x}$ exterioridade, cuidado exacerbado $\mathrm{x}$ desleixo, massa $\mathrm{x}$ cor, disciplina $\mathrm{x}$ vitalidade dispersiva”, oposições que, na prática, não poderiam ser tão categóricas nem revelariam tamanha nitidez (1956, p. 45).

Em contraposição, uma matéria publicada pouco antes, denominada A Complexa Escola de Paris, Gindertael também procurava diferenciar a praxe francesa da concorrente americana, mas também não aprofundava a questão. Esclarecia que, ao adotar o termo "complexo", queria referir-se a um composto de diferentes concepções e visões de mundo, geradoras de associações de idéias, de sentimentos e lembranças inconscientes, tão variados quanto eram os respectivos integrantes, o que tornava as gramáticas pictóricas diversificadas e singulares (1954, p.13-14).

Por sua vez, François-Albert Viallet iria admitir, mais pertinentemente, que o conceito de "Escola" não deixa de ser paradoxal, considerando que numerosos pintores mantiveram "uma concepção artística não só particular, mas tra- 
dicional, não renovando nem mesmo os temas e a técnica". Outros artistas, segundo ele, "chegaram à abstração através da deformação do objeto real, mantendo alguns elementos de evocação, ou certa referência ao mundo objetivo". Considerava, ainda, que embora a "não-figuração tenha como ideal a libertação da pintura do referente externo, através da transubstanciação da matéria pelo seu criador, para que a obra se transforme em uma nova e verdadeira criatura, para a maioria dos artistas franceses esses conceitos certamente não se aplicam. Mesmo que não tomem como modelo o real ou o alegórico, por pleitearem uma arte autônoma e inventiva, os franceses agem por simplificação, redução e despojamento das formas e das cores" (1957, p. 23-4).

A Escola de Paris continuaria sendo, ainda por muito tempo o assunto mais palpitante, acabando por desencadear o surgimento de vários livros, ensaios e a teses sobre a Abstração, extrapolando o âmbito dos periódicos, como foi o caso da reflexão elaborada por Laurence Vialatte de Pémille, destacando as qualidades e especificidades da mesma.

Numa época em que a arte abstrata americana já impunha internacionalmente a sua supremacia, a Abstração Informal ou Lírica francesa continuava não obtendo da crítica engajada mesmo no periódico especializado, um contra-ataque à altura.

A revista Art d'Aujourd'hui, por decisão de Léon Degand (antigo colaborador de revistas socialistas), procuraria reunir, em 1956, diferentes opiniões sobre o conceito de Arte Abstrata, em discursos articulados em resposta à questão: La peinture est-elle dans une situation critique? Seus principais interlocutores Pierre Guéguen e Guy Habasque iriam enveredar por um viés que contrapunha figuração e abstração, o que, além de não ampliar a reflexão sobre a arte abstrata francesa, não encontraria unanimidade de opiniões, acirrando os ânimos entre os próprios críticos.

Discorrendo sobre o mesmo tema Degand sustentaria a mesma linha de raciocínio que adotara no texto do catálogo da mostra inaugural do MAM paulista: Da Figuração à Abstração (1949). Traçava com grande desenvoltura e lucidez um panorama artístico circunstanciado, que começava no Impressionismo, detinha-se nas simplificações e geometrizações de Cézanne, na implosão das formas pelos pintores cubistas e pela questão da simultaneidade e da sugestão de movimento, engendrada pelos futuristas, para situar as raízes da abstração (DEGAND, 1956, p. 10-13). No entanto, o crítico não avançaria muito além da formulação de um in- 
ventário que postulava diferenças e semelhanças entre figuração e abstração. Esse mesmo balanço, embora com maior preciosismo, também prevaleceria no teor do livro publicado naquele mesmo ano por Degamd: Abstraction-Figuration: langage et signification, obra que já mereceu várias edições, e teve grande penetração no meio brasileiro.

Na tentativa de caracterizar a singularidade da poética dos abstracionistas líricos franceses, Georges Boudaille iria afirmar que eles nunca conceberam a pintura como pura invenção, mas como um diálogo profundo com o visível. A grande questão que se colocava para muitos artistas era, ainda segundo o crítico, fazer a difícil síntese entre os procedimentos à linguagem abstrata e os elementos extraídos da velha figuração. Citava como exemplo a produção de Bissière, Fautrier e Bazaine, concluindo que a premissa básica desses pintores resumia-se em "contar histórias improváveis, recorrendo a cores e a outros meios especificamente pictóricos" (1961, p. 39).

O crítico não deixava de ter razão, ao observar em parte das telas dos abstracionistas informais franceses o gesto introspectivo ou contido, expresso por pinceladas curtas, ou pequenos toques de cores e gestos, e nas quais ainda é possível apreender alguns resquícios da tradição. E talvez se possa dizer o mesmo das pinturas de alguns expressionistas abstratos, o que significa que, em sua verdadeira acepção, muitos artistas tidos como abstratos não comungaram única e exclusivamente dessas premissas, ao imbricarem nas composições elementos extraídos do mundo analógico, com certas formulações buscadas no imaginário e nos sonhos, em visível diálogo com o surrealismo. E ao atribuírem títulos às composições, tanto uns quanto outros induziam o espectador a estabelecer relações entre os códigos abstratos e os objetos e entes naturais, não negando o trânsito que estabeleciam entre figuração e abstração. Apesar de inegáveis diferenças formais que se desvelam nas obras de Bazaine, Bryen, Ubac, Mathieu, Esteve, Bazaine, Poliakoff, Vieira da Silva, Pollock, Mark Rothko, Hans Hofmann, Fautrier, Wols, Michaux, Dubuffet, Gorky, William Baziotes, Willem De Kooning, e do brasileiro Antônio Bandeira (então radicado em Paris), é possível buscar, ainda assim, alguma afinidade nas respectivas pinturas desses artistas, seja na maneira como cada um deles lida com as experiências pessoais e cotidianas, seja como se relacionam, direta ou indiretamente, com a tradição moderna. Assim, por razões que não cabe detalhar, o próprio conceito de abstração foi se modificando ao longo dos tempos, embora a idéia corrente de 
que a formulação da gramática abstrata constituía-se em uma espécie de simplificação das formas analógicas, até que a aparência configuradora das coisas desaparecesse, ou se tornasse menos evidente, permanecesse até muito recentemente.

Wols (alemão radicado na França) foi um dos articuladores da já citada Escola de Paris, iniciando-se na pintura a óleo por volta de 1946, embora realizasse aquarelas abstratas muito antes. Em suas telas escriturou com grande desenvoltura, uma caligrafia sígnica e gestos expressivos, que parecem extraídos do fundo de seu ser. No entanto, atribuiu às aquarelas e a algumas pinturas títulos que remetem, ora a aspectos do mundo objetivo ora ao imaginário, por meio de associações insólitas ou surrealistas, que parecem religar figuração e abstração.

Tal persistência figural foi assim ressaltada por Léon Degand, como uma peculiaridade de muitos pintores tidos como abstracionistas:

As primeiras pinturas qualificadas de abstratas, no sentido pictural não foram muitas vezes, é verdade, mais que pinturas figurativas ou, por eliminação, não por abstração, os signos mais evidentes de uma representação foram abolidos. E muitos são, ainda hoje, os pintores pretensamente abstratos que simplificam ou tornam irreconhecível o contorno de um nu, de uma janela ou de outros acessórios, eliminam um conjunto de linhas, desordenam as significações figurativas persistentes, substituindo esses signos por outros signos e por outras linhas, e cobrindo as superfícies assim obtidas por aplats de cores que evoquem, o menos possível, os objetos representados. Outros partem de uma idéia figurativa, que eles tomam o cuidado de não revelar de nenhuma maneira, para escapar das improvisações pictóricas onde o lirismo remete, ele próprio, à figuração, por transposições as mais desconcertantes. (1988, p. 183).

As telas de Hans Hartung, Pierre Soulages e Franz Kline, no entanto, colocavam-se quase como exceções ou oposições à maioria das sintaxes informais. As pinturas que os mesmos produziram revelam, em sua formulação, inteira liberdade na escrituração dos gestos impulsivos e impetuosos, parecendo distanciar-se de qualquer preocupação em estabelecer conexões com o referente, além deles não atribuírem títulos às respectivas telas.

Alguns articulistas da Cimaise, como foi o caso de François-Albert Viallet, se mostrariam cada vez mais convencidos 
de que para entender a abstração informal pictórica era necessário relacioná-la à "sensibilidade do homem atual", embora a argumentação utilizada nem sempre se revelasse coerente ou convicta. Assim, ao buscar respaldo em Bruno Brehm, com tal finalidade, o crítico destacaria alguns exemplos que pareciam mais condizentes com a racionalidade geométrica e não com a subjetividade da abstração informal, quando afirma: "da mesma maneira que quando o homem deixou de ser o centro do cosmos, sua efígie desapareceu da parede e da tela; a razão do florescimento da abstração em nossa época deve ser procurada na irrupção da mecanização universal que fundiu o homem com a máquina” (1959, p. 9).

Essa mesma postura seria assumida por Julien Alvard, articulista de Art D'Aujourd'hui e por Bernard Dorival, então diretor do Museu de Arte Moderna de Paris, no livro denominado Images de La Peinture Française (Édition Nomis), que ele acabava de publicar. Porém os mesmos iriam pôr em dúvida a existência e a contribuição da Escola de Paris para a formulação da abstração, contra o que iria se posicionar Léon Degand, em um texto denominado: "Por uma revisão de valores: Defensores da arte abstrata, não agravem a confusão!", que não apenas iria acirrar os ânimos, como dividir as opiniões a respeito da abstração, dando origem a uma avalanche de textos em vários órgãos da imprensa, que se pouco contribuiu para iluminar a reflexão sobre as linguagens abstratas, rompia com a acomodação e o marasmo da crítica parisiense, que se via instigada a discorrer mais intensamente sobre o assunto.

Nessa matéria denominada Degand, também lançava severas críticas ao recém publicado Dicionário da pintura moderna, de autoria de Michel Seuphor, pela editora Hazan, por entender que a obra confundia ainda mais o público. Entre outras questões, observava: "separar simplesmente arte abstrata e arte figurativa pretendendo que essa distinção seja suficiente para a compreensão das obras (...) é prova de sectarismo, de dogmatismo e de deselegância”, nada acrescentando à compreensão nem de uma nem de outra linguagem. Defendia que a abstração francesa, ao contrário do que propunha Seuphor, não deu as costas para o mundo exterior, considerando que dele extraiu alguns elementos, mesmo que eles não fossem "necessariamente físicos ou de identificação imediata". E concluía que, em qualquer das situações, a pintura era antes de tudo uma "criação pictórica que relaciona as formas e as cores sobre uma superfície plana, definida pelo pintor, segundo um processo que é ao mesmo tempo sensível e mental" (1957, p. 30). 
Passada a fase de caracterização da Escola de Paris, a preocupação das matérias críticas publicadas nas citadas revistas francesas passaria a deter-se na tentativa de conectar os códigos informais às micro-estruturas psíquicas. As reflexões de alguns iriam associar o fenômeno da poética abstracionista informal, às investigações realizadas nos diferentes campos do saber, e com as descobertas da nova ciência, que permitiram alargar o sentido de arte e de "natureza". Respaldaram-se, para isso, em idéias formuladas em escritos do lógico Stéphane Lupasco, constantes, em especial, em seus livros: Les Trois Matières; L'Energie et la Matière vivante e Science et Art Abstrait (publicados na época em Paris, por P. Julliard). Nessas obras, o cientista fazia alusão à "matéria inorgânica, à energia, que se desprende gradativamente até a sua dissolução total, e à matéria biológica, ou à vida que se desenvolve em sentido oposto", diante de cujas constatações ele descobria a fonte e o sentido da arte informal. Para Lupasco é possível estabelecer relações entre os procedimentos dos abstracionistas líricos e os adotados por cientistas e filósofos, mencionando, entre outros, os europeus Herbert Kuhn (L'Ascension de l'humanité, 1958) e o já citado Bruno Brehn (Das Ebennild, 1954), autores que, depois de analisarem as diferentes imbricações da cultura e das condições humanas concluíam que, o fenômeno da abstração artística não era novo, aparecendo em períodos e culturas diferenciados.

Tal tomada de posição não deixava de ser reveladora, pois a crítica francesa - ao contrário da americana que admitia ser o Expressionismo Abstrato tributário do Surrealismo de Masson e Gorky - não traçava, até então, qualquer afinidade da Abstração Informal com o Surrealismo. Os franceses tiveram dificuldade de acatar as idéias referentes à emergência do inconsciente e às correntes do pensamento irracional, enquanto critérios para a produção artística e cultural, na acepção que lhe atribuiu Merleau Ponty, para quem, "o inconsciente é consciência perceptiva", pois é através da percepção que o estabelecemos a ponte entre a experiência e o pensamento. Ainda segundo o filósofo, "à medida que a física 'objetivista' revelava seu fracasso, a psicologia fazia emergia os 'fatos subjetivos' ou 'fatos interiores ', postos não mais como ordens opostas, mas como dimensões de uma mesma realidade 'interior e exterior', 'mente e matéria' do ser, exigindo uma nova ontologia, e o reexame das noções de 'sujeito'e 'objeto'” (1984, p. 32-3).

Até o final dos anos de 1950, salvo raras exceções, não há nos escritos dos articulistas da revista Cimaise preocupação 
em centrar o discurso especificamente nos atributos poéticos e estéticos da Abstração Informal ou Lírica. Posição ainda menos coesa ou mesmo contraditória, assumiram os analistas críticos de Art d'Aujourd'hui, no que tange à tendência construtiva. Mas estes últimos mudariam de posição abandonando de vez os debates entre os defensores e os detratores da figuração e da abstração, articulando-se agora em torno de dois outros temas: uma parte passaria a defender a Abstração Geométrica e a rechaçar a vertente informal, enquanto a outra bajulava os adeptos da tendência lírica, rejeitando abertamente o concretismo, que denominavam de "linguagem racional e fria", posição que também seria adotada por críticos brasileiros como Mario Pedrosa. Entretanto, eles não iriam se espelhar nas especificidades e singularidades da própria pintura para fundamentar as respectivas críticas, nem procurar tornar compreensíveis e acessíveis essas linguagens ao público não iniciado, preferindo, colocar as pretensas vantagens de uma linguagem em detrimento da outras.

Percebendo tal tendência, Léon Degand também mudava seu ponto de vista, não sustentando ou por não sustentar mais a antiga preferência pelo léxico geométrico, ou por se mostrar agora menos cético em relação à pintura informal, assim discorrendo:

Embora se tenha buscado certa superioridade, e mesmo exclusividade, para a Abstração Geométrica, me parece estranho, e eu nunca acreditei mesmo, que, um gênero de formas possa ser menos adequado que outro para traduzir o pensamento plástico, uma vez que o que importa, nesse caso, não é a aparência da forma, mas a sua qualidade. (...) Essas exclusividades sempre me pareceram muito estranhas e nunca acreditei que um gênero de formas possa ser menos apto que outro para traduzir o pensamento plástico. A meu ver, é necessário que a forma traduza sempre exatamente o pensamento (1956, p.12-13).

Quando a arte abstrata informal dava evidentes sinais de seu esvaziamento no mundo e outras tendências muito mais radicais iam assumindo a cena artística, é que alguns críticos deixariam de escrever para a revista Art D'Aujourd'hui para publicar na $L^{\prime}$ Oeil (criada em 1956) mostrando-se mais conscientes dos exageros cometidos, até então, pela crítica francesa contra a abstração informal. Guy Habasque iria considerar a respeito que esse léxico, foi o que melhor traduziu a 
"evolução da arte moderna". Todavia, a maioria dos discursos continuava a se deter na busca das origens e não em questões específicas dessa poética, desviando-se do foco do problema, como iria observar o crítico: assim como não se pode explicar o "cubismo como uma reação ao impressionismo", são inteiramente inúteis e exasperadas as tentativas de opor Abstração Geométrica e Abstração Informal (1959, p.66).

Todavia, os embates com as gramáticas informais estavam longe de terminar, sem contar que repercutiram visivelmente nos discursos de alguns críticos brasileiros, conforme pontuaremos a seguir.

\section{Algumas considerações sobre a repercussão no Brasil dos discursos veiculados nas revistas de arte francesas}

As revistas francesas supracitadas, além de terem penetração nas instituições culturais brasileiras, integram hoje alguns acervos sob a guarda das mesmas, o que significa que despertaram interesse e repercutiram no ideário estético propugnado por alguns dos críticos mais atuantes no nosso país, nos anos 50, de modo especial nas reflexões daqueles que primeiro se filiaram a uma ou outra tendência abstracionista.

Os discursos veiculados em Art D'Aujourdh 'hui, parece ter influenciado, sobremaneira, o pensamento de Mario Pedrosa, enquanto o de Cimaise encontraria maior eco no também professor e crítico Mario Barata. Além do amplo trânsito internacional, que levou várias vezes os dois críticos a viajar à capital francesa, onde tiveram contato e se revelaram leitores dessas e de outras revistas europeias.

Ao retornar do exílio na metade dos anos 40, Mario Pedrosa iria incentivar artistas brasileiros a fazerem pesquisas pictóricas livres e mais ousadas do que as que já desgastadas figurações que adotavam até então. Pô-los em contato com algumas formulações abstratas internacionais, e instigava-os a empreenderem inclusive vôos ainda mais altos, recorrendo à tecnologia disponível na época, e a desenvolverem processos artísticos que sobrepujavam a pintura. No início da década de 1950, o crítico assumia posição declarada defesa em defesa do Concretismo, tornando-se um dos mais renitentes opositores da Abstração Informal.

Esse então professor da Faculdade de Arquitetura da Universidade do Brasil (Rio de Janeiro), durante uma das viagens que realizou a Paris concedeu entrevista a Edgard Pillet, arti- 
culista de Art D 'Aujourd 'hui (1953), quando traçou uma longa trajetória da gênese e desenvolvimento da abstração, remontando seus primórdios ao pensamento de Wölfflin, e pontuando a contribuição de Matisse, Cézanne, Klee, Kandinsky, Mondrian, Delaunay, Calder e Moholy-Nagy para a continuidade das pesquisas que culminariam na abstração. Atribuía ao último artista, o importante papel de "integrar o espaço à obra de arte, sem prejuízo de suas qualidades plásticas e sem fazer concessões à imitação da velha pintura".

Se naquele momento, o Concretismo firmava-se no Brasil, no restante do mundo já havia praticamente completado seu ciclo, o que levou o entrevistador a indagar Pedrosa sobre o futuro da arte abstrata. Confirmando o seu engajamento na defesa da arte concreta, o crítico afirmava estar convicto que "a arte abstrata apenas dava seus primeiros passos", o que lhe assegurava ainda um futuro longo. $\mathrm{E}$ conjeturava que até mesmo Max Bill, que se respaldara no pensamento matemático, "não passava de um primitivo" a balbuciar a "idéia de projeção, de vibração e de sucessão" das formas no espaço (PEDROSA, 1953, p. 14-15). ${ }^{5}$

Entretanto, os prognósticos do crítico brasileiro não iriam se confirmar. No final da década de 1950 (e apenas três anos após conceder essa entrevista), o Concretismo provocava contradições, divergências e confrontos entre seus próprios signatários, o que culminaria com a dissidência dos cariocas, quando saía da sombra e começaria a se impor a Abstração Informal. Com muita habilidade, no momento em que a tendência construtiva sinalizava a sua desarticulação e enunciava seu próprio esvaziamento, Mario Pedrosa, iria rever a posição e rapidamente parecia ter mudado de lado ou de preferência, prática adotada também por alguns críticos franceses, como vimos.

Em uma série de matérias, publicadas por ele no Jornal do Brasil, entre junho de 1959 e julho de 1960, tornava patente sua tolerância ou mesmo simpatia pela gramática informal. As pechas de "hedonismo" e "narcisismo" artístico, que dirigiu até pouco antes a essa poética pictórica, eram substituídas por "escritura pictórica", "caligrafia sígnica", "penetração intuitiva”, além de destacar nesse gênero abstracionista, o desvelar do gesto significativo do artista.

A reformulação do posicionamento do crítico ocorria após a permanência de cerca de dez meses no Japão, onde realizou estudos sobre a arte oriental, ${ }^{6}$ o que certamente contribuiu para essa mudança de posicionamento. $\mathrm{O}$ crítico parecia ter compreendido e se convencido da verdadeira acepção dos sig- 
nos caligráficos, que perpassam as pinturas de muitos artistas, com destaque para as telas dos imigrantes japoneses aqui radicados, como arquétipos ou signos culturais.

Assim, em uma dessas matérias, denominada "Iniciação à arte oriental", Pedrosa parecia procurar se redimir, ao chamar a atenção do homem ocidental para o significado da escrituração signográfica oriental:

Toda a arte chinesa e mesmo a japonesa é (...) iconográfica, isto é, feita em função de uma idéia ou símbolo. (...).

E, realmente, eis aí o único critério válido para a apreciação ocidental. Mas, então, devemos perguntar a nós mesmos: De onde pode vir num apreciador ocidental essa indispensável 'penetração intuitiva'? É claro: da 'análise e da apreciação formal' . Aliás, ainda filosoficamente falando, só há um meio de se manipular direito o perigoso conceito de intuição - é através da revelação de uma forma. Se o ocidental abre mão dessa análise, dessa apreciação formal, incapacita-se para apreciar e avaliar, e muito menos julgar, qualquer obra, e principalmente a oriental (1959, s.p.).

Em outro artigo, publicado posteriormente no mesmo periódico, o crítico, embora não se referisse ainda à produção dos abstracionistas informais ou líricos brasileiros, revelava simpatia pelo tachismo francês, de Hartung e Soulages, por entender que eles se debatiam "entre a pureza ancestral do signo e a necessidade por assim dizer cultural ou social de superá-lo". Destacava também na pintura gestual de Pollock, o que chamava de "signo-raio, que fende o espaço: impossível de ser detido", e chamava atenção para o exercício corporal que o artista empreendia para formular a tessitura sígnica gotejada de suas telas "com o signo inicial uma trama; mais do que uma trama, um ritmo, mais do que um ritmo um bailado" (PEDROSA, 196o, s.p.). ${ }^{7}$

Em outro conjunto de textos publicados no início de 1960, também no Jornal do Brasil, Mario Pedrosa não deixava dúvida de que conhecia realmente, tanto os discursos mal digeridos da crítica francesa sobre a Abstração, como parecia ratificar as reflexões postuladas ao longo deste texto:

...Paris se havia deixado ficar para trás no que diz respeito à arte abstrata em geral. Enquanto Kandinsky, Klee, Mondrian, Malevitch e outros mestres do abstracionismo já tinham sido 
consagrados nos Estados Unidos, cujos museus e galerias contêm coleções completas desses mestres, na Alemanha, sobretudo em Berlim, Kassel, Munique, e na Suíça (...), Paris continuava a desconhecê-los e desprezá-los.

E depois dos primeiros movimentos abstracionistas, outros movimentos de mesma tendência apareceram, uma segunda geração de abstracionistas surgiu sem que Paris, oficial, ou mesmo seus críticos mais titulados se dignassem sair de seu desdém provinciano, continuando a pôr em dúvida a legitimidade da arte abstrata (196o, s.p.). ${ }^{8}$

O crítico também externava decepção com a escolha da representação de artistas brasileiros para a Bienal de Veneza, acusando os membros da comissão de "saírem a catar tachistas para que o Brasil se apresente, sem qualquer originalidade, como um país culturalmente subdesenvolvido”. E aproveitava a oportunidade para tecer também críticas à escolha dos pintores informais selecionados para a Bienal de São Paulo, afirmando que "só três tinham bagagem para essa representação: Manabu Mabe, Bandeira e Tanaka” (PEDROSA, s.p). ${ }^{9}$ Nesse sentido talvez se possa afirmar que a crítica de Pedrosa não era dirigida à Abstração Informal, como um todo, mas àquilo que ele chamava de "inconsistente" e destituído de "originalidade".

Entretanto, não se deve descartar também o impacto que teria causado na crítica brasileira, a publicação na revista l'Oeil (abril de 1959), do já emblemático ensaio de autoria de Georges Mathieu, denominado $D^{\prime}$ Aristote. Nesse texto, o francês traçava um longo percurso histórico, para pontuar as origens seminais da linguagem informal, que chamava de “arte sígnica”, relacionando-a com os efeitos da destruição provocada pela explosão da bomba atômica em Hiroshima e com a revolução da ciência moderna. Segundo Matthieu, ao postular a permutação dialética matéria/energia e a gravitação das forças eletro/magnéticas, a ciência moderna iria contribuir para que "a Física, tanto quanto a pintura se voltassem para a procura de uma estrutura interna” (1959, p. 29)..$^{10}$ Essa reflexão, que tece conexões entre ciência moderna e subjetividade poética também integrou os discursos de outros críticos e exerceu notável influência na crítica francesa, contribuindo para ampliar a compreensão da Abstração Informal ou Lírica, como já citado. 


\section{Referências}

ALVARD, J. "Alguns jovens americanos em Paris. Aujourd'hui », Paris, 6 juin, 196, p. 25-28.

BOUDAILLE, G. "Bissière", Cimaise (54), jul, ago, 1961, p. 39 e 47.

BORDIER, R. "La peinture est-elle dans une situation critique?", Art D'Aujourd'hui (6), jan. 1956, p. 6-8.

CRISPOLTI, Enrico. L'Informale: Storia e Poética. Assisi/Roma: Beniamino Carucci, 1971, p. 24.

DAVAL, J.L. Histoire de la peinture abstraite. Paris: Fernan Hazan, 1988, p.127.

DEGAND, L. Abstraction-Figuration :langage et signification de la Peinture. Int Daniel Abadie. Paris : Cercle d'Art, 1988, p . 183 . "La peinture est-elle dans une situation critique?", Art D'Aujourd'hui (6), jan. 1956,pp. 12-13.

. "Pour uma révision des valeurs: défenseurs de l'art abstrait, n'aggravez pas la confusion!", Aujourd'hui (13), juin 1957, p. 30.

GINDERTAEL, R. V. “Le Complexe d'École de Paris", Cimaise (2), nov./dez., 1954, p. 13-14.

GREENBERG, Clement "Pintura à americana ", in FERREIRA, Glória e MELLO, Cecília C. de. Clement Greenberg e o debate crítico,. 1997, p. 75 e 94.

GUÉGUEN, P.. "La peinture est-elle dans une situation critique?", Art D 'Aujourd 'hui (6), jan. 1956, p. 14-17;

GULLAR, Ferreira "Manifesto tachista na revista L'Oeil ", Jornal do Brasil, 7 jun. 1959, s.p..

HABASQUE, G. «Au-delà de l'informel ». L'Oeil (59), Paris, nov. 1959, pp. 62-66.

"La peinture est-elle dans une situation critique?", Art D'Aujourd 'hui (6), jan. 1956, p. 18-21;

LEBENSZTEJN, J. C. « assage: notes sur les idéologies de la première abstraction ». In Les Cahiers du Musée National d'art moderne. Paris : Centre Pompidou, n. 108, 2009, p. 8-29.

MATHIEU, G. "D'Aristote", L'Oeil (32), avril 1959, p. 29-35

MERLE AU-PONTY, M. O Visível e o invisível. São Paulo: Perspectiva, 1984, p.32-3.

PEDROSA, M. “Arte Signográfica”, Jornal do Brasil, 5 ago. 1959, s. p..

. "Chega de clandestinidade", Jornal do Brasil (RJ), 12 março 1960, s.p. 
mar. 1960, s.p..

"Em busca de tachistas", Jornal do Brasil, 18

. "Imperialismo Artístico", Jornal do Brasil (RJ), o6

jan. 1960, s. p..

. "Iniciação à arte oriental", Jornal do Brasil (RJ), 10

jun. 1959, s.p.

. "Pour un large débat", Interview de M. a

Edgard Pillet, Art d'Aujourd 'hui (8), Paris, déc. 1953,

p. 14-16.

SIKES, G. "La peinture est-elle dans une situation critique?", Art D'Aujourd 'hui (6), jan. 1956, p. 22-23;

VIALLET, F. A., LUPASCO, S.. "Science et Art Abstrait", Cimaise (6-7), jan./fev./mar, 1964, p. 57.

VIALLET, F. A. " Compréhension et incompréhension de l'art abstrait ». Cimaise, Paris, mars/abril, 1959, p. 9-20

.Rôle, dangers et chances de l'Art Abstrait" Cimaise (2 e 6), nov e dez. 1957, p. 23-30

WESCHER, H. "L'Art Abstraite", Cimaise (7-8), jun, jul, ago, 1956, p. 45-47.

\section{NOTAS}

1. Entre outros artistas que teriam chegada à Abstração, na mesma época de Kandinsky, é citado Adolf Hölzel, que em 1905 pintara Komposition in Rot (Composição em Vermelho), óleo s/tela, 68x85 cm, no Museu Sprengel, em Hanover.

2. Nessa época, o partido comunista francês aderia ao chamado Kominform - Agência de Informação dos Partidos Comunistas e Negócios, que irmanava os sete países da chamada Cortina de Ferro, do Leste europeu, mais o partido comunista italiano, contra os Estados Unidos. Visava combater especialmente a propaganda doutrinária do Presidente Truman (1947) e o plano Marshall (1948-1956), que oferecia apoio econômico à reconstrução da Europa, estratégia para barrar a penetração do comunismo no Ocidente.

3. Dessa exposição participaram Bryen, Gorky, Hartung, De Kooning, Mathieu, Picabia, Pollock, Reihnardt, Rthko, Russel, Sauer, Tobey e Wols.

4. Escreveram para a revista, entre outros críticos: R. V. Gindertael, Michel Ragon, Herta Wecher, Dore Ashton, Michel Seuphor, Pierre Restany, Daniel Abadie, Pierre Cabanne.

5. Nessa entrevista, o crítico não tratou especificamente do concretismo no Brasil. Entretanto, embora sem citar o nome de Palatnik, referia-se a pinturas com luz, desenvolvidas no Brasil, por meio de "um aparelho capaz de projetar visões luminosas no espaço de uma tela", não suscitando dúvida de que se tratava do "Aparelho Cinecromático".

6. Pedrosa viajou com uma bolsa da UNESCO, mediante indicação da AICA - Associação Internacional de Críticos de Arte, durante a realização de um congresso em Palermo (Itália). 
7. Id. , “Arte Signográfica”, Jornal do Brasil, 5 ago. 1959.

8. Id. "Imperialismo artístico", Jornal do Brasil (RJ), o6 jan. 196o, s. p.

9. Mario Pedrosa, "Chega de clandestinidade", Jornal do Brasil (RJ), 12 março 196o. Todavia, poucos dias depois, o crítico manifestava-se decepcionado com as obras de Tanaka (artista que adotou depois o nome de Shiró-Tanaka), que, segundo ele, apresentava uma pintura "ruim" e "inacabada", para representar o país em evento internacional do Museu Guggeheim, em Nova Yorik. Sobre o assunto vide: M. Pedrosa, "Em busca de tachistas", Jornal do Brasil, 18 março 1960.

10. O texto foi traduzido e transcrito com o título de "Georges Mathieu fala da Arte e das Ciências", na Tribuna da Imprensa (Rio de Janeiro), 6 nov. 1959 e era objeto também de comentários por parte de Ferreira Gullar, "Manifesto tachista na revista L'Oeil", Jornal do Brasil, 7 jun. 1959.

Recebido em: 11/12/11

Aceito em: 27/02/12 


\section{ALMERINDA DA SILVA LOPES}

aslopes@npd.ufes.br

Doutora em Artes Visuais pela PUC/SP. Estágio pós-doutoral na Universidade de Paris I. Professora de História da Arte no Brasil no Centro de Artes e do Programa de Pós-Graduação - Mestrado em Arte da Universidade Federal do ES. Pesquisadora de Produtividade do CNPq. Membro do CBHA e ANPAP. Autora de livros e outras publicações, com enfoque na arte moderna e contemporânea. 